\title{
Estudo dos fatores condicionantes do índice de desenvolvimento humano nos municípios do estado do Paraná: instrumento de controladoria para a tomada de decisões na gestão governamental*
}

\author{
Jorge Eduardo Scarpin** \\ VAlmor Slomski***
}

SUMÁRIO: 1. Introdução; 2. Referencial teórico; 3. Metodologia; 4. Resultados da pesquisa; 5 . Considerações finais.

Summary: 1. Introduction; 2. Theoretical framework ; 3. Methodology; 4. Research results; 5. Final remarks.

Palavras-chave: IDH; controladoria pública; gestão pública.

KEY WORDS: HDI; public accounting; public management.

Este artigo aponta uma modelagem matemática para determinar o valor futuro do IDH-M para os municípios do Paraná, com base em dados contábeis atuais e outras variáveis. O referencial teórico abrange, entre outros, as-

\footnotetext{
* Artigo recebido em out. 2005 e aceito em nov. 2006.

** Doutor em controladoria e contabilidade pela Universidade de São Paulo (USP), mestre em engenharia de produção pela Universidade Federal de Santa Catarina (USC), mestre em contabilidade e controladoria pela Universidade Norte do Paraná, docente do Mestrado em Ciências Contábeis da Universidade Regional de Blumenau. Endereço: Universidade Regional de Blumenau — Rua Antônio da Veiga, 140 - Victor Konder - CEP 89012-900, Blumenau, SC, Brasil. E-mail: jorgescarpin@furb.br.

$* * *$ Mestre e doutor em controladoria e contabilidade pela Universidade de São Paulo (USP). Docente do Mestrado e Doutorado em Controladoria e Contabilidade da Universidade de São Paulo (USP). Endereço: USP — Faculdade de Economia, Administração e Contabilidade Departamento de Contabilidade Atuária - Av. Prof. Luciano Gualberto, 908 - Prédio FEA 3 - Sala 234 - Cidade Universitária - CEP 05508-900, São Paulo, SP, Brasil. E-mail: valmor@usp.br.
} 
pectos de externalidades e bens públicos, analisando as razões pelas quais são necessários investimentos públicos e também contempla aspectos sobre o cálculo do IDH-M. O artigo é baseado em uma pesquisa explicativa, e o instrumental utilizado é a análise de regressão, com regressões múltiplas a partir de 87 variáveis independentes, sendo 10 variáveis não-contábeis e 77 contábeis. Fica evidente que o IDH-M possui relação com as variáveis de IDH-M passado, distância em relação à capital, altitude, nível de população rural, receita tributária, despesa com pessoal, despesa com saúde e saneamento, investimentos e gastos com indústria e comércio.

Conditioning factors of the human development index of municipalities in the state of Paraná, Brazil: an accounting tool for public management decision making

This article presents a mathematical model for determining the future value of local HDI of municipalities in the state of Paraná, Brazil, based on current accounting data and other variables. The theoretical framework considers externalities and public assets, analyzing the reasons why public investments are necessary, as well as how the HDI is calculated. This explanatory research uses regression analysis with multiple regressions of 87 independent variables, 10 of them non-accounting and 77 accounting variables. The tests showed that local HDI has relation with past local HDI variables, distance to the state capital, altitude, level of rural population, tax revenue, expenses with civil service personnel, public health and sanitation expenditure, investments and expenses with commerce and industry.

\section{Introdução}

No início da década de 1990, foi lançado pela ONU o índice de desenvolvimento humano (IDH), que se propõe a verificar o grau de desenvolvimento de um país utilizando alguns indicadores de desempenho. O IDH logo passou a ser a mais conhecida medida de desenvolvimento humano (Torres, Ferreira e Dini, 2003).

Valendo-se do sucesso do IDH, as Nações Unidas tornaram-se capazes de sinalizar, aos governantes dos diversos países e regiões em desenvolvimento, a proposição de que buscar crescimento não é sinônimo exclusivo de fazer aumentar o produto interno bruto. Com isso, tem sido possível constituir um considerável debate internacional a respeito de que, pelo menos, a melhoria das condições de saúde e educação da população deve também ser considerada parte fundamental do processo de desenvolvimento.

A construção desse indicador de desenvolvimento reflete a estreita relação com os debates em torno da mensuração da qualidade de vida. A rigor, um 
indicador sobre esse tema se baseia na admissão de que a qualidade de vida não se resume à esfera econômica da experiência humana. A grande questão que se coloca quando se pretende avaliar o nível de prosperidade ou qualidade de vida de um país, região ou município é como fazê-lo e quais os critérios verdadeiramente significativos para o desenvolvimento humano.

É possível que a medida de qualidade de vida mais difundida, até o surgimento do IDH, tenha sido o PIB per capita. No entanto, conhecer o PIB per capita de um país ou região não é suficiente para avaliar as condições de vida de sua população, pois é necessário conhecer a distribuição desses recursos e como se dá o acesso a eles.

Esse entendimento, de que o PIB per capita é uma medida insuficiente para avaliar a qualidade de vida das pessoas, já estava evidente na década de 1950 quando de acordo com Torres, Ferreira e Dini (2003:80) "em 1954 um grupo de especialistas das Nações Unidas propôs que, além da dimensão monetária, outras dimensões deveriam ser consideradas na avaliação da qualidade de vida das pessoas".

Essa idéia se baseia no pressuposto de que o progresso de um país ou município não pode ser mensurado apenas pelo dinheiro que seus cidadãos possuem (ou carecem), mas também pela sua saúde, a qualidade dos serviços médicos e a educação. Essas medidas devem ser consideradas não só pela disponibilidade, mas também pela qualidade. Também é necessário conhecer as condições de trabalho, de quais direitos legais e políticos usufruem seus cidadãos, que liberdades possuem para conduzir suas relações sociais e pessoais, como se estruturam as relações familiares e entre os gêneros e como tais estruturas promovem ou dificultam outros aspectos da atividade humana.

Nos últimos 400 anos, as cidades têm crescido e se modernizado, contribuindo para o desenvolvimento em suas regiões e de forma indireta ao mundo de forma geral. Hoje, a cidade reflete parte de uma sociedade globalizada atuando como um ponto numa rede de informações totalmente interligadas. Entretanto, qualquer que seja a aparência de uma cidade hoje ou em tempos passados, ela sempre formou o berço da civilização.

A civilização propriamente dita começou por volta de 3000 a.C. na Mesopotâmia. Mumford citado por Freitag (2001) defende algumas teses interessantes sobre a origem das cidades. Entre outras, afirma que a cidade dos mortos antecedeu a cidade dos vivos. As verdadeiras fundadoras de cidades e civilizações teriam sido as mulheres, que cultuavam seus mortos em lugares aos quais, mesmo em períodos de nomadismo, voltavam com regularidade erguendo santuários para aqueles que já tinham morrido. Além disso, as mulheres ainda procuravam lugares seguros e protegidos para dar à luz. 
As cidades são, de acordo com Verhoef e Nijkamp (2003:5), "o centro de um centro de ação socioeconômico, confrontação humana, dialética política, nascedouro da civilização, centros de ciência e arte e um pote de mistura de culturas".

Sendo a cidade tão importante, é função do Estado garantir que seus cidadãos possam conviver da forma mais harmoniosa possível uns com os outros. Para tanto, há a arrecadação de tributos ${ }^{1}$ pelo Estado junto aos cidadãos e o posterior gasto para a maximização do bem-estar da população. Em tese, quanto maior o gasto, maior o nível do bem-estar.

Há muito tempo estabeleceu-se a prática de avaliar o bem-estar de uma população, e conseqüentemente de classificar os países ou regiões, pelo tamanho de seu PIB per capita. Entretanto, o progresso humano e a evolução das condições de vida das pessoas não podem ser medidos apenas por sua dimensão econômica.

Por isso existe uma busca constante por medidas socioeconômicas mais abrangentes, que incluam também outras dimensões fundamentais da vida e da condição humana.

O IDH, criado no início da década de 1990 para o Pnud (Programa das Nações Unidas para o Desenvolvimento), é uma contribuição para essa busca, e combina três componentes básicos do desenvolvimento humano: a longevidade, que reflete, entre outras coisas, as condições de saúde da população, medida pela esperança de vida ao nascer; a educação, medida por uma combinação da taxa de alfabetização de adultos e a taxa combinada de matrícula nos níveis de ensino fundamental, médio e superior; e a renda, medida pelo poder de compra da população, baseado no PIB per capita ajustado ao custo de vida local para torná-lo comparável entre países e regiões, por meio da metodologia conhecida como paridade do poder de compra (PPC).

Analisando o perfil do IDH municipal e a possível contribuição da contabilidade pública no sentido de registrar adequadamente o nível dos gastos públicos, surge a seguinte questão: as informações provenientes da contabilidade pública possuem valor preditivo na determinação do IDH do município?

Para prover resposta às questões de pesquisa, este artigo tem como objetivo geral apontar uma modelagem matemática para determinar o valor futuro do IDH-M para os municípios do Paraná, com base em dados contábeis atuais e outras variáveis.

A preocupação com os efeitos dos gastos públicos na economia é constante nos nossos governantes, sobretudo com os impactos sobre o crescimento

\footnotetext{
${ }^{1}$ Por tributos, entenda-se impostos, taxas e contribuições de melhorias.
} 
econômico. A população espera melhor utilização dos recursos, pois existem limites para a expansão das receitas que financiam o aumento dos gastos per capita. Outra restrição importante ocorre nos países em processo de estabilização econômica, onde o ajuste fiscal é peça fundamental da política macroeconômica. Isso reforça a necessidade de aumento da eficiência dos gastos públicos.

Diversos trabalhos teóricos e empíricos, como Ram (1986), Barro (1990), Cashin (1995) e Ascahuer (1989) entendem que os gastos públicos podem elevar o crescimento econômico por meio do aumento da produtividade do setor privado. Os serviços de infra-estrutura (transportes, telecomunicações e energia) e a formação de um sistema legal e de segurança, que preservem os direitos de propriedade e a defesa nacional, são alguns exemplos de atividades que servem de insumos para o setor privado. Além disso, a recente teoria do crescimento endógeno ressalta o fato de as externalidades positivas dos bens públicos e semipúblicos elevarem os retornos privados, a taxa de poupança e acumulação de capital, uma vez que, se não fosse pelo governo, esses bens seriam subofertados. Por outro lado, uma expansão dos gastos públicos financiados por impostos distorcivos e a ineficiência na alocação dos recursos podem superar o efeito positivo dessas externalidades. Adicionalmente, autores como Srinivasan (1985), Buchanan citado por Cândido (2001) e Bhagwati (1982) defendem a idéia de que os gastos públicos são improdutivos e não geram nenhum produto adicional porque são apenas resultantes de interesses de grupos.

No Brasil, estudos recentes também exploram efeitos do capital público sobre o crescimento econômico e a produtividade. Ferreira (1996) e Ferreira e Malliagros (1998) encontram evidências de uma forte relação entre investimentos em infra-estrutura (energia, telecomunicações e transportes) e produto. Segundo esses trabalhos, a elasticidade-renda de longo prazo desses investimentos varia de 0,55 a 0,70. Já os trabalhos de Rocha e Teixeira (1996) e de Cruz e Teixeira (1999) analisam a relação entre investimentos públicos e privados, tentando identificar relações de complementaridade ou de substituição. No entanto, nenhum desses autores capta os efeitos dos gastos públicos totais sobre o produto.

O objetivo deste artigo é o de apontar uma modelagem matemática para determinar o valor futuro do IDH-M para os municípios do Paraná, com base em dados contábeis atuais e outras variáveis.

Buscamos, assim, contribuir com a elaboração de novos conhecimentos relativos ao impacto dos gastos públicos na formação do IDH-M, com o intuito de poder direcionar as políticas públicas, de modo que possam alocar seus recursos da forma mais eficiente possível, para criar um município cada vez mais desenvolvido. 


\section{Referencial teórico}

\section{Externalidades e bens públicos}

A discussão sobre o papel da intervenção governamental na economia, para fins de alocação eqüitativa dos recursos da sociedade, tem como embasamento a teoria dos bens públicos para a justificativa da alocação dos recursos nacionais entre o setor público e privado, para fornecimento de parte de bens requeridos pela população. Essa teoria visa analisar a eficiência na utilização dos recursos pelo setor público.

A externalidade é definida por Pindyck e Rubinfeld (1994:904) como a "ação de um produtor ou consumidor que afete outros produtores ou consumidores, entretanto não levada em consideração no preço de mercado".

As externalidades podem surgir entre produtores, entre consumidores, ou entre produtores e consumidores. De acordo com Kon (1997:35) "as externalidades positivas representam as economias nos custos produtivos e os benefícios para os agentes que as usufruem, enquanto as negativas ou deseconomias se associam a prejuízos, aumentos nos custos, desvantagens", também chamadas de benefício externo (externalidade positiva) e custo externo (externalidade negativa). Em outras palavras, as externalidades negativas ocorrem quando a ação de uma das partes impõe custos sobre a outra e as externalidades positivas, quando a ação de uma das partes beneficia a outra.

Pelo fato das externalidades não estarem refletidas nos preços de mercado, elas poderão se tornar uma causa de ineficiência econômica, resultando em uma externalidade negativa. Por outro lado, as externalidades podem também resultar em níveis insuficientes de produção, gerando uma externalidade positiva.

Na presença de externalidades, o interesse da sociedade em relação a um resultado de mercado vai além do bem-estar de compradores e vendedores do mercado, incluindo também o bem-estar das demais pessoas afetadas. Mankiw (2001:208) afirma que "como compradores e vendedores negligenciam os efeitos externos de suas ações ao decidir quanto demandar ou ofertar, o equilíbrio de mercado não é eficiente na presença de externalidades". Isso significa que o equilíbrio de mercado não consegue maximizar o benefício total para a sociedade como um todo.

Entre os mecanismos existentes para a correção da alocação ineficiente de recursos em um mercado provocado por uma externalidade estão as políticas públicas. Kon (1997) diz que a intervenção governamental no sistema econômico, freqüentemente, tem como objetivo a criação, manutenção e aprimoramento de externalidades positivas; e a eliminação, correção e contro- 
le de externalidades negativas. O fornecimento de bens e serviços públicos cria externalidades positivas para uma parcela da sociedade, representadas por economias de urbanização ou de aglomeração. No entanto, elas estão sujeitas a se transformarem em deseconomias quando ultrapassarem um tamanho considerado "ótimo" de concentração urbana, levando à deterioração dos bens e serviços públicos. Mas a deterioração pode demorar mais ou menos tempo para se fazer sentir, pois cada tipo de bem ou serviço público apresenta uma capacidade ou limite, além do qual a interferência mútua entre os consumidores se torna notável e aumenta desproporcionalmente à oferta pelo governo. Mesmo no caso de "bens livres", ou seja, os fornecidos pela natureza, a ação humana pode aumentar a capacidade de sua utilização ou ultrapassar o limite de possível fruição.

As políticas públicas podem ser divididas em política de regulamentação e políticas baseadas no mercado. Na regulamentação, o governo pode solucionar uma externalidade tornando certos comportamentos exigidos ou proibidos, como exigir que não se jogue resíduo tóxico em mananciais de água, ou fazendo leis de controle da poluição.

Além da regulamentação, o governo pode trabalhar com impostos ou incentivos privados, tributando as atividades que geram externalidades negativas e subsidiando aquelas que geram externalidades positivas.

Também há que se considerar que a eficiência do mercado está presente nos bens privados. Entretanto, existem diversos outros bens além dos privados, que são: bens públicos, monopólios naturais e recursos comuns.

Os bens públicos não são nem excluíveis nem rivais. Mankiw (2001:228) define exclusibilidade como "a propriedade de um bem por meio da qual se pode impedir uma pessoa de usá-lo" e rivalidade como "a propriedade de um bem por meio da qual sua utilização por uma pessoa impede a outra de o utilizar". Em virtude disso, não se pode impedir as pessoas de desfrutarem dos bens públicos, e um bem público pode ser desfrutado por várias pessoas sem prejuízo de nenhuma delas. Wonnacott e Wonnacott (1994:104) afirmam que bem público puro "tem benefícios que não podem ser negados a ninguém, mesmo aos que não tenham pago pelo bem".

A principal característica dos bens públicos, que os distingue dos privados, como explica Rezende (2001:84), "refere-se à impossibilidade de excluir determinados indivíduos ou segmentos da população de seu consumo, uma vez definido o volume de produção".

A produção de um bem público pode tanto ser feita por agentes públicos ou privados. Pindyck e Rubinfeld (1994:878) defendem que "a produção de um bem público pelo governo é vantajosa porque este pode avaliar os impostos ou tarifas que deverão ser responsáveis pelo pagamento de tal bem". Por 
sua vez, a alocação de recursos públicos na produção de um bem público é algo complexo, já que, segundo Kon (1997:153) “os consumidores não revelarão suas preferências e não farão lances, pois podem usufruir os mesmos benefícios independente do pagamento ou dos lances que determinem". Como, nesse caso, o sistema de mercado não funciona, a alocação de recursos para o fornecimento desses bens é da alçada de uma decisão política.

Wonnacott e Wonnacott (1994:94) citam uma frase de Abraham Lincoln bastante elucidativa sobre o tema: "um objetivo legítimo do governo é fazer o que precisa ser feito para os cidadãos e que estes não podem fazer por si sós como indivíduos, ou que não podem fazer tão bem como o governo". Entretanto, o debate sobre uma intervenção maior ou menor do governo na economia não é consensual na literatura. Przeworsky (1996) organiza o debate sobre a eficiência da intervenção do Estado na economia como uma luta de boxe, debates que andam em círculos e nos quais os argumentos sobre os defeitos do mercado são respondidos com argumentos sobre os fracassos das tentativas de regulamentação. Tendo o mercado vencido o primeiro round como o mais eficiente alocador de recursos, perdeu o segundo quando houve consenso sobre suas falhas (bens públicos, externalidades e monopólios), e ganhou o terceiro round ao acusar o Estado de ter excedido suas funções de corrigir essas falhas e afirma que nada garante que o Estado não apresente falhas piores.

Entretanto, ainda segundo Przeworsky (1996), o mercado equilibrado e eficiente dos neoclássicos já foi ferido de morte e formas de intervenção estatal são inevitáveis, pois a economia de mercados incompletos e informação imperfeita abre espaço para que o Estado desempenhe papel muito mais amplo.

Wonnacott e Wonnacott (1994:94) expõem que o "governo afeta a economia de quatro maneiras básicas: despesas, impostos, controles e empresas estatais". As decisões do governo em gastar, taxar, regular ou estabelecer uma empresa estatal influenciam diretamente, afinal as decisões são pautadas pela ótica de quais produtos e serviços serão produzidos pela economia, como e para quem.

A expansão dos gastos públicos se relaciona com o seu papel de produção dos bens públicos e de controle de externalidades numa economia de mercado, visto que, como explica Rezende (2000:119), "dada a incapacidade de os mercados organizarem-se eficientemente para produzir os bens públicos, os governos tendem a permanecer se expandindo".

É preciso que a controladoria governamental desenvolva seu papel que, de acordo com Slomski (2005:15), é o de desenvolver mecanismos "pelo atingimento do ótimo em qualquer ente, seja ele público ou privado, é o algo mais procurado pelo conjunto de elementos que compõem a máquina de qualquer entidade". 


\section{Índice de desenvolvimento humano municipal}

O IDH é uma medida-resumo do desenvolvimento humano. Mede a realização média de um país em três dimensões básicas do desenvolvimento humano. De acordo com Fukuda-Parr e co-autores (2004), as três dimensões são:

- uma vida longa e saudável, medida pela esperança de vida à nascença;

v conhecimento, medido pela taxa de alfabetização de adultos (com ponderação de $2 / 3$ ) e pela taxa de escolarização bruta combinada do primário, secundário e superior (com ponderação de 1/3);

、 um nível de vida digno, medido pelo PIB per capita (dólares PPC — paridade de poder de compra).

Fukuda-Parr e co-autores (2004:258) apresentam a estruturação do IDH global de acordo com a figura.

Dimensão, indicador e índice de dimensão do IDH global

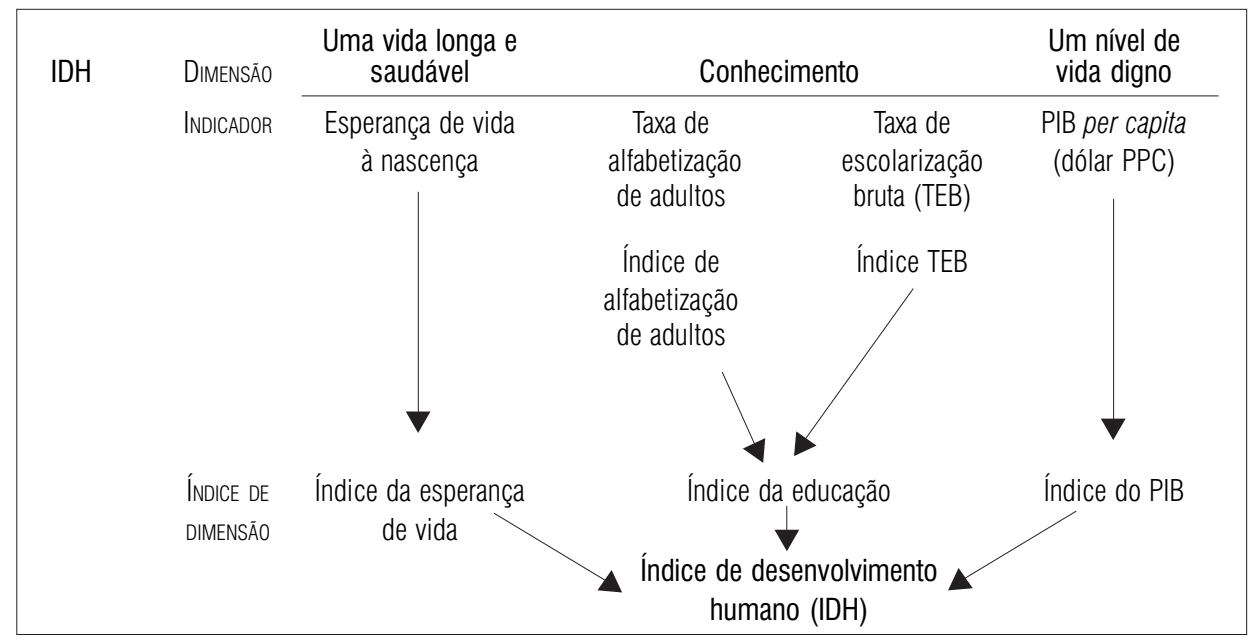

Fonte: Fukuda-Parr et al., 2004:258.

Antes de calcular o próprio IDH, é necessário criar um índice para cada uma dessas três dimensões. Para o cálculo dos indicadores de dimensão índices de esperança de vida, educação e PIB - são escolhidos valores mínimos e máximos (balizas) para cada indicador primário. $\mathrm{O}$ desempenho em cada indicador varia de zero (valor mínimo) a um (valor máximo). O procedimento de cálculo para os índices é: 


$$
\text { Índice de dimensão }=\frac{\text { valor atual }- \text { valor mínimo }}{\text { valor máximo }- \text { valor mínimo }}
$$

A primeira dimensão estudada pelo IDH é chamada de uma vida longa e saudável. Tal dimensão é obtida pelo cálculo de um único índice, chamado índice de esperança de vida. Segundo Fukuda-Parr e co-autores (2004:259), esse índice mede "a realização relativa de um país na esperança de vida à nascença".

A segunda dimensão estudada pelo IDH é chamada de conhecimento e é avaliada pelo índice da educação, composto de dois índices, o índice da alfabetização de adultos e o da escolarização bruta combinada. $\mathrm{O}$ índice da alfabetização de adultos mede o percentual de adultos alfabetizados. Por sua vez, o índice da escolarização bruta engloba tanto a educação no primário como no secundário e superior.

De posse dos dois índices, é feita então uma ponderação para o cálculo do índice da educação. É atribuída uma ponderação de $2 / 3$ à alfabetização de adultos e de $1 / 3$ à escolarização combinada.

As dimensões renda e educação devem ser correlacionadas entre si. Mankiw, Romer e Weil (1992) verificaram uma significância estatística entre nível de educação e PIB per capita em uma amostra cross-sectional de 98, 75 e 22 países, enfatizando o relacionamento positivo entre os indicadores. De modo alternativo, Bils e Klenow (2000) mostram que o investimento em educação é provavelmente uma função de ganhos financeiros atuais e futuros.

Por fim, há a terceira dimensão, a do nível de vida digno. Nessa dimensão, o índice do PIB é calculado utilizando o PIB per capita ajustado (dólares PPC). Fukuda-Parr e co-autores (2004:259) explicam que, no IDH, "o rendimento entra como um substituto para todas as dimensões do desenvolvimento humano não reflectidas numa vida longa e saudável e no conhecimento". O rendimento é ajustado porque, para alcançar um nível elevado de desenvolvimento humano, não é necessário um rendimento ilimitado. Por isso, utiliza-se o logaritmo do rendimento.

As dimensões do nível de vida digno e da educação também podem ser interdependentes. Biswas e Caliendo (2002:2) afirmam que "uma alta expectativa de vida fornece um incentivo adicional para se obter educação". Esses autores também mencionam que "a educação pode render frutos para o aumento da expectativa de vida". Uma análise estatística feita por eles mostra um índice de correlação da ordem de 0,82.

Uma vez calculados os índices das três dimensões, para efetuar o cálculo do IDH basta fazer a média aritmética dos índices. 


\title{
A controladoria e o índice de desenvolvimento humano municipal
}

Em seu aspecto fundamental, Slomski (2005:15) define controladoria como a busca pelo atingimento do ótimo em qualquer ente, seja ele público ou privado. É o algo mais, procurado pelo conjunto de elementos que compõem a máquina de qualquer entidade. Slomski (2003:373) também argumenta que nas entidades públicas, "a controladoria terá como missão disseminar conhecimento, modelar e implementar sistemas de informações capazes de responder aos usuários das informações econômico-físico-financeiras". Cabe à controladoria garantir a perfeita realização do processo de decisão, ação, informação e controle, acompanhando e controlando as atividades da empresa.

Sob a ótica da controladoria, Pereira (1999:57) afirma que

\begin{abstract}
a gestão caracteriza-se pela atuação em nível interno da empresa que procura otimizar as relações recursos-operação-produtos, considerando as variáveis dos ambientes externo e interno que impactam as atividades da empresa, em seus aspectos operacionais, financeiros, econômicos e patrimoniais.
\end{abstract}

Assim, serão destacadas as interações entre o modelo de gestão, o processo de gestão e os sistemas de informações como elementos que desempenham papel fundamental para assegurar a eficácia dos gestores e, conseqüentemente, da empresa.

Bianchi e Nascimento (2005) explicam que uma administração ideal pode encontrar suas bases no modelo de gestão, materializado por meio do processo de gestão da empresa cujos mecanismos devem assegurar a sua eficiência e eficácia e, como conseqüência, propiciar a redução de conflitos dentro de uma organização. Entre os vários elementos componentes desse processo, destaca-se o planejamento, com suas diversas fases, bem como as bases de controle.

O planejamento existe porque existem tarefas a serem cumpridas, atividades a serem desempenhadas, e o desejo de fazer isso da forma mais econômica possível, coordenando o uso dos diferentes recursos, humanos, materiais, financeiros e tecnológicos, cada um a seu tempo, com especificidades próprias e o intuito de fazer com que seus objetivos sejam atingidos.

Oliveira (2004:44) apresenta cinco partes de um planejamento:

v planejamento dos fins - especificação do estado futuro desejado, ou seja, a missão, os propósitos, os objetivos, os objetivos setoriais, os desafios e as metas; 
v planejamento dos meios - proposição de caminhos para a empresa chegar ao estado futuro desejado. Aqui se tem a escolha de macroestratégias, macropolíticas, estratégias, políticas, procedimentos e práticas;

v planejamento organizacional - esquematização dos requisitos organizacionais para poder realizar os meios propostos;

v planejamento dos recursos - dimensionamento de recursos humanos e materiais, determinação da origem e aplicação de recursos financeiros;

v planejamento da implantação e controle - corresponde à atividade de planejar o gerenciamento da implantação do empreendimento.

Porém, o planejamento em si pode ser somente um instrumento inanimado de administração e não servir ao propósito de diminuição dos conflitos entre principal e agente, se não for visto apenas como uma das peças de um sistema de controle organizacional mais amplo.

A questão de conflitos entre principal e agente nasceu da verificação da separação entre o proprietário de uma empresa privada e a sua gestão, efetuada por profissionais remunerados. E o dilema desse conflito é que os interesses desses profissionais remunerados podem não convergir com os dos proprietários em função de eles terem seus próprios objetivos, tendendo, por isso, a "favorecer estratégias na empresa que aumentem suas chances de carreira e remuneração, em vez de maximizar o valor da empresa" (Merret et al., apud Cia, Guarita e Cia, 2002:2).

Esse conflito de interesse, também chamado de conflito de agência, observado na relação "patrão-empregado", foi a origem dos estudos que culminaram no desenvolvimento da teoria da agência, cuja contribuição para as ciências sociais aplicadas, mais especificamente, administração, contabilidade e economia, tem sido fomentar investigações sobre os meios adequados para reduzir os mencionados conflitos.

Nesse cenário, a controladoria, como explicam Bianchi e Nascimento (2005), pode contribuir com a teoria da agência pelo fato de poder monitorar um sistema de informação, de mensuração de resultados e reportar suas observações ao principal e, também, ao agente, fornecendo informações relevantes ao principal sobre as ações dos agentes, dados históricos e a probabilidade de ocorrências futuras.

Na esfera pública municipal, apesar de não haver um proprietário formal do município, existem diversos conflitos de agência. Pode-se considerar como proprietários do município os seus habitantes que, por meio de eleições livres, escolhem o seu prefeito, que será o administrador do município em um período determinado de tempo. Mas pode acontecer de o interesse do prefeito 
não ser o mesmo interesse dos munícipes, fato que, por si só, já caracteriza um clássico conflito de agência.

Um dos maiores interesses dos munícipes é a maximização do desenvolvimento humano da coletividade, sendo que tal desenvolvimento é medido pelo IDH-M.

Para que o interesse dos munícipes seja alcançado, é dever do administrador eleito pela população gerir as finanças públicas de modo que os gastos possam fazer com que haja uma maximização do desenvolvimento, visto que os gastos públicos possuem relação com desenvolvimento, seja na questão da redução de externalidades negativas, seja na questão dos bens públicos.

Logo, se os gastos públicos e, por conseqüência a receita pública, afetam o desenvolvimento de um município, é função da controladoria municipal a elaboração de sistemas de informação para acompanhamento da receita e dos gastos municipais, para a verificação do comportamento do IDH-M local, visto que, conforme Sousa, Soares e Leal (2005:2) "é atribuição da controladoria dar suporte informacional em todas as etapas do processo de gestão, com vistas a assegurar o conjunto de interesses da empresa".

Tais suportes informacionais são fundamentais para a eliminação desse conflito, visto que o administrador público pode ter outros interesses que não a maximização do desenvolvimento, mas sim a espoliação do patrimônio público para fins próprios, direcionamento de gastos para aliados políticos, uma futura reeleição ou eleição para outros cargos públicos, como deputado, senador, governador etc.

O suporte informacional se dá por via de um sistema integrado de informações que tem por objetivo, como explica Padoveze (2004:51), "a consolidação e aglutinação de todas as informações necessárias para a gestão do sistema empresa".

Além de a controladoria ser responsável pelo acompanhamento e controle dos gastos públicos para o crescimento do IDH-M, também é função da controladoria estabelecer meios de previsão do impacto que os gastos públicos futuros vão trazer ao IDH-M, para auxiliar em todas as etapas da gestão pública, pois, apesar do IDH-M não ser mensurado pelas variáveis contábeis, o mesmo pode ser impactado por elas.

A figura da previsão, desde que elaborada com critérios científicos, pode trazer benefícios para qualquer entidade, seja pública ou privada, visto que é capaz de antever resultados futuros. Os resultados podem ser tanto financeiros, como receita, custos, lucros etc., quanto físicos, como quantidade vendida, taxas de mortalidade, acidentes em estradas, disseminação de doenças etc. A previsão do valor futuro do IDH-M trabalha tanto com fatores financeiros, 
no caso a dimensão renda, quanto com fatores não-financeiro, como as dimensões educação e longevidade.

\section{Metodologia}

Para Rudio (1993:9) “a fim de merecer o qualitativo de científica, a pesquisa deve ser feita de modo sistematizado, utilizando método próprio e técnicas específicas e procurando um conhecimento que se refira à realidade empírica". Realidade empírica para o autor é "tudo que existe e pode ser conhecido por meio da experiência".

Neste artigo, a busca das respostas à questão-problema deu-se, fundamentalmente, por meio de pesquisa explicativa. Segundo Gil (1999), a pesquisa explicativa tem como principal objetivo identificar os fatores que determinam ou contribuem para a ocorrência dos fenômenos. Por explicar a razão e o porquê das coisas, esse é o tipo de pesquisa que mais aprofunda o conhecimento da realidade.

Na visão de Andrade (2002), a pesquisa explicativa é mais complexa, pois além de registrar, analisar, classificar e interpretar os fenômenos estudados, identifica seus fatores determinantes. Tem por objetivo aprofundar o conhecimento da realidade, procurando a razão, o porquê das coisas e por esse motivo está mais sujeita a erros. A hipótese geral que delimita o campo dessa pesquisa é: $\mathbf{H}_{0}$ - as informações provenientes das finanças públicas não possuem valor preditivo na determinação do IDH do município.

A abordagem da pesquisa é de natureza quantitativa-qualitativa. A quantitativa foi utilizada a fim de desenvolver a modelagem matemática para determinar as variáveis financeiras que possuem relação com o IDH, evidenciar a temporalidade das informações financeiras no IDH, bem como prever valores futuros do IDH com base em variáveis financeiras. Por sua vez, a abordagem qualitativa foi adotada para dar base e parametrizar os resultados quantitativos, visando a uma melhor análise geral do caso.

Conforme Minayo (1993), nenhuma das duas abordagens é suficiente para a compreensão completa da realidade. O melhor método é aquele que permite a construção correta do modelo que deve refletir a dinâmica da teoria a ser proposta. Os dois métodos são complementares. Neste artigo, utilizamos uma pesquisa documental. Para Lüdke e André (1986:38), “a análise documental pode ser uma técnica valiosa de abordagem de dados qualitativos, seja complementando as informações obtidas por outras técnicas, seja desvendando aspectos novos de um tema ou problema". Colauto e Beuren (2003:140) explicam que "o propósito dessa análise é fazer inferências sobre os valores, os sentimentos, as intenções e a ideologia das fontes dos autores dos documen- 
tos. Indica ainda, quais problemas devem ser melhor explorados por outros métodos".

A coleta de dados teve fontes primárias e secundárias. Lakatos e Marconi (2001:159) citam que fontes primárias são "dados históricos, bibliográficos e estatísticos; informações, pesquisas e material cartográfico; arquivos oficiais e particulares; registros em geral; documentação pessoal etc.”. Fontes secundárias são "imprensa em geral e obras literárias".

Foram obtidas duas espécies de dados primários para a pesquisa. A primeira diz respeito a dados sobre o índice de desenvolvimento humano municipal. A segunda, aos dados financeiros necessários para a pesquisa, obtidos no site do Tesouro Nacional.

Em relação às fontes secundárias, foi feita revisão da literatura para dar suporte ao desenvolvimento do tema. Pesquisamos teses de doutorado, dissertações de mestrado, artigos publicados, livros nacionais e estrangeiros, além de materiais obtidos junto a órgãos relacionados ao índice de desenvolvimento humano.

A pesquisa foi feita pelo cruzamento dos dados do IDH-M no ano de 2000, disponível no software Atlas do Desenvolvimento Humano do Brasil, versão 1.0.0, com dados de variáveis financeiras municipais disponíveis no site do Tesouro Nacional; por meio do software Finanças do Brasil (Finbra), bem como por outras informações não-financeiras, disponíveis no software Atlas do Desenvolvimento Humano do Brasil, versão 1.0.0, no Instituto Brasileiro de Geografia e Estatística (IBGE), no Instituto Paranaense de Desenvolvimento Econômico e Social (Ipardes) e também no site do governo do estado do Paraná.

A população pesquisada é os 398 municípios do estado do Paraná. ${ }^{2}$ Para a amostra, foram extraídos 370 municípios. Os 28 municípios restantes foram excluídos da amostra, visto não haver a possibilidade de obtenção dos seus dados para as variáveis financeiras.

A técnica estatística selecionada para o objetivo deste artigo foi análise de regressão. Por meio dessa técnica foi possível calcular o nível de sensibilidade entre as informações financeiras e o índice de desenvolvimento humano municipal (IDH-M). Ressaltamos que, para todos os testes estatísticos foi utilizado um nível de significância de 5\%. Para o processamento dos cálculos estatísticos nas regressões foi também utilizado o software SPSS for Windows, com exceção dos testes de normalidade, nos quais foi usado o software BestFit for Windows.

\footnotetext{
${ }^{2}$ Totalidade dos municípios do estado do Paraná, segundo o censo de 2000 do IBGE.
} 
Foram testados os pressupostos da regressão, de acordo com Corrar e co-autores (2004): multicolinearidade das variáveis independentes, normalidade dos resíduos, autocorrelação serial e heterocedasticidade.

\section{Variáveis}

De acordo com a hipótese elaborada, foram selecionadas oito variáveis dependentes e 87 variáveis independentes foram selecionadas para a pesquisa.

A variável dependente foi baseada nos valores do IDH-M do ano de 2000. Para explicar as variáveis dependentes, foram selecionadas 87 variáveis independentes, considerando-se variáveis financeiras e não-financeiras para o aprofundamento do estudo em questão. Como os municípios possuem populações de tamanhos muito díspares, há o problema de escala, e a necessidade de ajustar algumas variáveis pelo tamanho da população, trabalhando com seu valor per capita.

As variáveis não-financeiras utilizadas no modelo são: IDH-M de 1991 em todas as suas dimensões; altitude; densidade demográfica em 2000; distância à capital; população rural nos anos de 1991 e 2000; população urbana nos anos de 1991 e 2000 e a taxa de variação da população total entre os anos de 1991 e 2000. Por sua vez, as variáveis financeiras utilizadas no modelo são as receitas e despesas públicas de 1997 a 2000.

Todo tipo de pesquisa possui limitações. Marconi e Lakatos (1999:31) afirmam que um dos limites para a investigação é que "nem sempre se pode abranger todo o âmbito no qual o fato se desenrola". Aqui as principais limitações baseiam-se no fato de que o Atlas do Desenvolvimento Humano do Brasil traz os índices de desenvolvimento humano municipal nos anos de 2000 e 1991, não sendo possível portanto traçar uma longa série histórica; além disso a pesquisa se restringiu ao estado do Paraná. Por isso, seus resultados não podem ser extrapolados para o restante dos estados da federação.

Apesar dessas limitações, as conclusões obtidas por meio do estudo cuidadoso e de critérios científicos adotados no desenvolvimento do trabalho, todavia, não são invalidadas por essas limitações, sendo possível a conclusão sobre a relevância da informação financeira no IDH-M, bem como a sua predição com base nas variáveis financeiras.

\section{Resultados da pesquisa}

Apresentaremos os resultados da pesquisa para os modelos de previsão de IDH-M futuro, com a análise dos modelos de regressão para estimar quais 
variáveis independentes, com suas respectivas temporalidades, impactam o IDH-M futuro na sua forma total.

A pesquisa foi feita com dois modelos distintos. O primeiro modelo apresentou o resultado da regressão linear múltipla contemplando o IDH-M como variável dependente e as demais variáveis como independentes. Já o segundo modelo apresentou uma regressão para cada dimensão do IDH-M (educação, longevidade e renda) e depois obtivemos a equação do IDH-M, considerando a média aritmética entre as equações das três dimensões.

\section{Modelo 1}

O primeiro modelo a ser testado possui como variáveis independentes o índice de desenvolvimento humano municipal do ano de 1991, o índice de desenvolvimento humano municipal na dimensão educação do ano de 1991, a distância à capital $(\mathrm{km})$, o nível de receita tributária per capita no ano de 2000, o índice de desenvolvimento humano municipal na dimensão longevidade do ano de 1991, a despesa de pessoal do ano de 1997 e a altitude do município (m), sem considerar nenhuma outra variável.

Em relação aos pressupostos, os testes para a heterocedasticidade, autocorrelação serial e normalidade dos resíduos tiveram resultados satisfatórios.

Em relação à multicolinearidade das variáveis independentes, houve a presença nas variáveis relacionadas ao IDH-M passado, sendo que para todas as outras, os resultados foram satisfatórios.

As estatísticas da regressão para este modelo estão na tabela 1.

\begin{tabular}{|lccc|}
\hline \multicolumn{4}{|c|}{ Estatísticas do modelo - IDH-M total } \\
\hline $\mathrm{R}$ & $\mathrm{R}$ quadrado & $\mathrm{R}$ quadrado ajustado & Erro-padrão da regressão \\
\hline 0,924 & 0,853 & 0,850 & $1,534 \mathrm{E}-02$ \\
\hline
\end{tabular}

O modelo tem um coeficiente de determinação ajustado bastante significativo, que explica $85 \%$ do IDH-M futuro.

No resultado da Anova, o modelo apresentou-se com a rejeição da hipótese nula dos coeficientes das variáveis independentes em conjunto serem iguais a zero, com um valor do teste F igual a 300,124 e com Sig igual a 0,000.

Os coeficientes da regressão para esse modelo apresentaram os resultados e estatísticas apresentados na tabela 2 . 


\begin{tabular}{|lccccc|}
\hline \multicolumn{5}{c}{ Tabela 2} \\
Coeficientes & modelo & & & \\
\cline { 2 - 5 } & & IDH-M total & & \\
\hline Coeficientes & Beta & Std. Error & T & Sig \\
\hline (Constante) & 0,217 & 0,015 & 14,661 & 0,000 \\
Índice de desenvolvimento humano municipal 1991 & 0,363 & 0,061 & 5,971 & 0,000 \\
Índice de desenvolvimento humano municipal - & & & & \\
educação - 1991 & 0,274 & 0,037 & 7,429 & 0,000 \\
Distância à capital (km) & $3,856 \mathrm{E}-05$ & 0,000 & 4,545 & 0,000 \\
Receita tributária 2000 & $1,470 \mathrm{E}-04$ & 0,000 & 5,277 & 0,000 \\
Índice de desenvolvimento humano municipal - & & & & \\
longevidade - 1991 & $8,602 \mathrm{E}-02$ & 0,030 & 2,889 & 0,004 \\
Despesa de pessoal 1997 & $4,140 \mathrm{E}-05$ & 0,000 & 2,614 & 0,009 \\
Altitude da sede (m) & $1,110 \mathrm{E}-05$ & 0,000 & 2,249 & 0,025 \\
\hline
\end{tabular}

Os índices apresentaram relevâncias estatísticas boas, com Sig inferior a $5 \%$, porém as três últimas variáveis a serem adicionadas apresentaram uma significância diferente de zero. Como o modelo apresenta multicolinearidade com três, continua a ser observada a menor relevância do IDH-M na dimensão educação em relação ao IDH-M na dimensão total, embora o índice seja significativo também e o IDH-M na dimensão longevidade apresente um beta bem menos significativo. Ressaltamos que a constante ficou levemente menor em relação ao modelo anterior, o que mostra apenas um reagrupamento nos coeficientes. Os comportamentos das variáveis são todos positivos em relação ao IDH-M total, o que mostra que os municípios mais altos tendem a apresentar IDH-M melhor do que os municípios mais ao nível do mar. O modelo apresentou a seguinte fórmula para previsão do IDH-M futuro:

\footnotetext{
IDH-M $2000=0,217+0,363$ x IDH-M $1991+$ 0,274 x IDH-M educação + 3,856E-05 x distância à capital $+1,470 \mathrm{E}-04 \times$ receita tributária $2000+8,602 \mathrm{E}-02 \times$ IDH-M longevidade $+4,140 \mathrm{E}-05 \times$ despesa com pessoal $1997+1,110 \mathrm{E}-05 \times$ altitude da sede $(\mathrm{m})$
}

Pela fórmula fica evidente que o IDH futuro será apenas 36,3\% do IDH passado, 27,4\% do IDH passado na dimensão educação e 8,602E-02 do IDH-M passado na dimensão longevidade, o que mostra também uma possível perda deste indicador com o passar do tempo, o que não é bom para os municípios do Paraná, embora já se tenham outras três variáveis com um poder explicativo para o auxílio na previsão. 


\section{Modelo 2}

A segunda modelagem foi o desenvolvimento de um modelo para cada dimensão do IDH-M e depois a elaboração da equação de previsão.

Em relação à dimensão educação, foi encontrada uma equação de previsão com as seguintes variáveis independentes: IDH-M educação passado e investimentos de 1998, obtendo um coeficiente de determinação ajustado igual a 0,85.

Já na dimensão longevidade, foi encontrada uma equação de previsão com as seguintes variáveis independentes: IDH-M longevidade passado, IDHM educação passado, saúde e saneamento do ano de 1997, distância à capital $(\mathrm{km})$ e despesas com indústria e comércio do ano de 1998, obtendo um coeficiente de determinação ajustado igual a 0,53.

Por fim, na dimensão renda, foi encontrada uma equação de previsão com as seguintes variáveis independentes: IDH-M passado, IDH-M longevidade passado, o percentual da população rural no ano de 2000, a receita tributária do ano de 2000, a despesa com agricultura do ano de 1997, despesas com juros e encargos da dívida do ano de 1998 e despesa com saúde e saneamento do ano de 1997, obtendo um coeficiente de determinação ajustado igual a 0,81.

Em relação aos pressupostos, os testes para a heterocedasticidade, autocorrelação serial e normalidade dos resíduos tiveram resultados satisfatórios em todas as modelagens.

As fórmulas de previsão do IDH-M em cada dimensão são:

$$
\begin{aligned}
& \text { IDH-M educação }=0,322+0,702 \times \text { IDH-M educação passado }+4,798 \mathrm{E}-05 \text { x investimentos com } \\
& \text { defasagem de três anos }
\end{aligned}
$$

IDH-M renda $=0,215+0,946 \times$ IDH-M passado $-0,268 \times$ IDH-M longevidade passado $-2,796 \mathrm{E}-02 \times$ população rural $+1,321 \mathrm{E}-04 \times$ receita tributária do ano corrente

Aplicando-se a mesma metodologia para o cálculo do IDH-M, a fórmula resultante para o IDH-M no período foi:

\footnotetext{
IDH-M = 0,232 + 0,315 x IDH-M passado + 0,322 x IDH-M educação passado + 9,367E-02 x IDH-M longevidade passado $+1,104 \mathrm{E}-05 \times$ distância à capital $-9,320 \mathrm{E}-03 \times$ população rural $+4,403 \mathrm{E}-05 \times$ receita tributária do ano corrente $+8,147 \mathrm{E}-05 \times$ despesa com saúde e saneamento com defasagem de quatro anos $+1,104 \mathrm{E}-05 \mathrm{x}$ investimentos com defasagem de três anos $-8,163 \mathrm{E}-05 \mathrm{x}$ indústria e comércio com defasagem de três anos
} 
Apesar de as duas fórmulas terem o mesmo propósito, e muitas vezes coeficientes semelhantes, elas possuem algumas diferenças fundamentais, como evidenciado na tabela 3 .

\begin{tabular}{|lcc|}
\hline \multicolumn{3}{|c|}{ Tabela 3} \\
Comparação das fórmulas do IDH-M futuro \\
\hline Variável & IDH-M total & IDH-M por componente \\
\hline Constante & 0,217 & 0,232 \\
IDH-M passado & 0,363 & 0,315 \\
IDH-M educação passado & 0,274 & 0,322 \\
IDH-M longevidade passado & $8,602 \mathrm{E}-02$ & $9,367 \mathrm{E}-02$ \\
Distância à capital & $3,856 \mathrm{E}-05$ & $1,104 \mathrm{E}-05$ \\
Altitude da sede & $1,110 \mathrm{E}-05$ & - \\
População rural & - & $-9,320 \mathrm{E}-03$ \\
Receita tributária do ano corrente & $1,470 \mathrm{E}-04$ & $4,403 \mathrm{E}-05$ \\
Despesa com pessoal com defasagem de quatro anos & $4,140 \mathrm{E}-05$ & - \\
Despesa com saúde e saneamento com defasagem de quatro anos & - & $8,147 \mathrm{E}-05$ \\
Investimentos com defasagem de três anos & - & $1,104 \mathrm{E}-05$ \\
Indústria e comércio com defasagem de três anos & - & $-8,163 \mathrm{E}-05$ \\
\hline
\end{tabular}

A previsão pelo modelo de regressão apresentou a constante e mais sete variáveis, sendo três relacionadas ao próprio IDH-M, duas relacionadas a fatores físicos e duas variáveis contábeis. A previsão pelos componentes do IDH$\mathrm{M}$, por sua vez, trouxe a constante e mais nove variáveis, sendo também três relacionadas ao próprio IDH-M, duas relacionadas a fatores físicos, entretanto, trouxe quatro variáveis contábeis.

\section{Análise dos resultados}

Para garantir a acurácia do modelo, foi feito um teste com os 10 maiores municípios paranaenses, bem como os 10 menores. Nesse teste foi comparado o IDH-M de 2000 com o valor previsto para o IDH-M de 2000 com a primeira e com a segunda fórmulas, bem como os seus respectivos erros absolutos.

$\mathrm{O}$ resultado encontrado para os 10 maiores municípios paranaenses foi o que segue, na tabela 4, ressalvando o fato que o município de Colombo, o oitavo maior município paranaense não fez parte da amostra, por falta de dados, e foi acrescentado o município de Apucarana, o décimo primeiro maior município paranaense. 


\begin{tabular}{|c|c|c|c|c|c|c|}
\hline \multicolumn{7}{|c|}{$\begin{array}{l}\text { Tabela } 4 \\
\text { Acurácia da previsão }-10 \text { maiores municípios }\end{array}$} \\
\hline Município & $\begin{array}{l}\text { População } \\
\text { total }\end{array}$ & $\begin{array}{l}\text { IDH-M } \\
2000\end{array}$ & $\begin{array}{c}\text { Previsão } \\
\text { fórmula } 1\end{array}$ & $\begin{array}{l}\text { Resíduo } \\
\text { absoluto }\end{array}$ & $\begin{array}{c}\text { Previsão } \\
\text { fórmula } 2\end{array}$ & $\begin{array}{l}\text { Resíduo } \\
\text { absoluto }\end{array}$ \\
\hline Curitiba & 1.587 .315 & 0,856 & 0,861 & 0,005 & 0,849 & 0,007 \\
\hline Londrina & 447.065 & 0,824 & 0,829 & 0,005 & 0,821 & 0,003 \\
\hline Maringá & 288.653 & 0,841 & 0,835 & 0,006 & 0,825 & 0,016 \\
\hline Ponta Grossa & 273.616 & 0,804 & 0,796 & 0,008 & 0,797 & 0,007 \\
\hline Foz do Iguaçu & 258.543 & 0,788 & 0,797 & 0,009 & 0,791 & 0,003 \\
\hline Cascavel & 245.369 & 0,810 & 0,807 & 0,003 & 0,798 & 0,012 \\
\hline São José dos Pinhais & 204.316 & 0,796 & 0,797 & 0,001 & 0,793 & 0,003 \\
\hline Guarapuava & 155.161 & 0,773 & 0,776 & 0,003 & 0,775 & 0,002 \\
\hline Paranaguá & 127.339 & 0,782 & 0,789 & 0,007 & 0,793 & 0,011 \\
\hline Apucarana & 107.827 & 0,799 & 0,790 & 0,009 & 0,786 & 0,013 \\
\hline Valores médios & & 0,807 & 0,808 & 0,006 & 0,803 & 0,008 \\
\hline
\end{tabular}

\section{Considerações finais}

Este artigo teve como objetivo geral apontar uma modelagem matemática para determinar o valor futuro do IDH-M para os municípios do estado do Paraná, com base em dados contábeis atuais e outras variáveis. A pesquisa foi realizada com os municípios de Paraná, com os dados obtidos junto ao Atlas de Desenvolvimento Humano e ao Tesouro Nacional.

Para a elaboração da previsão, foram feitas regressões anuais para a determinação do relacionamento entre o IDH-M com diversas variáveis financeiras e não-financeiras.

Por meio de um conjunto de modelos e de regressões para a evidenciação dos fatores condicionantes do IDH-M, foram obtidas as seguintes conclusões: os modelos mostraram que as informações contábeis possuem relevância na determinação do IDH-M; a modelagem matemática para a determinação do IDH-M futuro foi alcançada; pela fórmula apresentada na pesquisa, observam-se variáveis contábeis relevantes na determinação do IDH-M, tanto pelo modelo regressivo direto, quanto pelos modelos regressivos de análise de cada componente em particular; foram encontradas, finalmente, diferenças temporais nas variáveis contábeis quando da determinação do IDH-M futuro. As defasagens mais comuns foram entre três e quatro anos, dependendo da variável utilizada.

Este artigo teve como principal contribuição propor uma fórmula para a determinação do IDH-M baseado em variáveis contábeis e também em variá- 
veis não-contábeis, bem como evidenciar que o nível de desenvolvimento humano de um município é impactado pelas receitas e despesas públicas. Logo, um bom gerenciamento das contas públicas tende a fazer com que os municípios tenham seu nível de desenvolvimento humano aumentado ao longo dos anos.

Finalmente, a controladoria governamental, valendo-se de instrumentos como a modelagem matemática de previsão do índice de desenvolvimento humano municipal pode oferecer subsídios para que a administração pública atinja o ponto ótimo de desenvolvimento humano para determinado município.

Assim, concluímos que os objetivos deste artigo foram atingidos em todos os seus aspectos, com a evidenciação das variáveis contábeis e nãocontábeis responsáveis pelo IDH-H nos municípios do estado do Paraná, bem como a evidenciação da temporalidade das receitas e gastos públicos no impacto do IDH-M.

Ressaltamos, entretanto, que os dados referem-se apenas ao estado do Paraná, não podendo ser estendidos ao conjunto de estados da federação, que podem apresentar resultados diversos dos encontrados neste artigo. Em virtude disso, recomendamos futuras pesquisas com os demais estados brasileiros para a verificação de uma congruência ou não dos resultados encontrados.

\section{Referências bibliográficas}

ANDRADE, Maria Margarida. Como preparar trabalhos para cursos de pós-graduação: noções práticas. 5. ed. São Paulo: Atlas, 2002.

ASCAHUER, D. Is public expenditure productive? Journal of Monetary Economics, v. 23, Mar. 1989.

ATLAS do Desenvolvimento Humano do Brasil - versão 1.0.0. 2003. Disponível em: <www.pnud.org.br/atlas>. Acesso em: 25 fev. 2005.

BARRO, R. A Government spending in a simple model of endogenous growth. Journal of Political Economy, v. 98, Oct. 1990.

BHAGWATI, J. Directly unproductive profit-seeking DUP activities. Journal of Political Economy, v. 90, n. 5, 1982.

BIANCHI, Márcia; NASCIMENTO, Auster Moreira. A controladoria como um mecanismo interno de governança corporativa e de redução dos conflitos de interesse entre principal e agente. In: CONGRESSO INTERNACIONAL DE CUSTOS, 9., Itapema, 2005. Anais... Itapema, 2005.

BILS; Mark; KLENOW, P. Does schooling cause growth. American Economic Review, v. 90, n. 5, Dec. 2000. 
BISWAS, Basudeb; CALIENDO, Frank. A multivariate analysis of the human development index. Indian Economic Journal, v. 49, n. 4, Apr./June 2002.

CÂNDIDO, José Oswaldo Júnior. Os gastos públicos no Brasil são produtivos? Pesquisa e Planejamento Econômico, Ipea, n. 23, jun. 2001.

CASHIN, P. Government spending taxes and economic growth. IMF Staff Papers, v. 42, n. 2, p. 237-269, June 1995.

CIA, Josilmar Cordenonssi; GUARITA, Celeste Indio; CIA, Joanília Neide de Sales. O duplo papel do investidor institucional: influenciador do Corporate Governance e gestor de carteiras. In: ENCONTRO NACIONAL DOS PROGRAMAS DE PÓS-GRADUAÇÃO EM ADMINISTRAÇÃO - ENANPAD, 26., Salvador, Bahia, 2002. Anais... Salvador, Bahia, 2002.

COLAUTO, Romualdo Douglas; BEUREN, Ilse Maria. Coleta, análise e interpretação dos dados. In: BEUREN, Ilse Maria (Org.). Como elaborar trabalhos monográficos em contabilidade: teoria e prática. São Paulo: Atlas, 2003.

CORRAR, Luiz J.; THEÓPHILO, Carlos Renato; BERGMANN, Daniel Reed. Regressões. In: ; _. (Orgs.). Pesquisa operacional para decisão em contabilidade e administração. São Paulo: Atlas, 2004.

CRUZ, B.; TEIXEIRA, J. The impact of public investment on private investment in Brazil 1947-1990. CEPAL Review, v. 67, Apr. 1999.

FERREIRA, P. Investimento em infra-estrutura no Brasil. Fatos estilizados e relações de longo prazo. Pesquisa e Planejamento Econômico, Ipea, v. 26, n. 2, ago. 1996.

; MALLIAGROS, T. Impactos produtivos da infra-estrutura no Brasil - 1950/95. Pesquisa e Planejamento Econômico, Ipea, v. 28, n. 2, ago. 1998.

FREITAG, Barbara. Utopias urbanas. In: ENCONTRO DA SOCIEDADE BRASILEIRA DE SOCIOLOGIA, 10., Fortaleza, Ceará, set. 2001. Anais... Fortaleza, Ceará, 2001.

FUKUDA-PARR et al. Relatório do desenvolvimento humano 2004 - liberdade cultural num mundo diversificado. Lisboa: Mensagem, 2004.

GIL, Antônio Carlos. Métodos e técnicas de pesquisa social. 5. ed. São Paulo: Atlas, 1999.

IBGE (Instituto Brasileiro de Geografia e Estatística). Informações sobre dados estatísticos nacionais. Disponível em: <www.ibge.gov.br>. Acesso em: 21 mar. 2005.

IPARDES (Instituto Paranaense de Desenvolvimento Econômico e Social). Informações sobre dados estatísticos do estado do Paraná. Disponível em: <www.pr.gov.br/ipardes>. Acesso em: 15 abr. 2005.

KON, Anita. Subsídios teóricos e metodológicos ao planejamento econômico público. Eaesp/ FGV/NPP - Núcleo de Pesquisas e Publicações. Relatório de pesquisa, n. 12, 1997. 
LAKATOS, Eva Maria; MARCONI, Maria de Andrade. Fundamentos de metodologia científica. 4. ed. São Paulo: Atlas, 2001.

LÜDKE, Menga; ANDRÉ, Marli E. D. A. Pesquisa em educação: abordagens qualitativas. São Paulo: EPU, 1986.

MANKIW, N. Gregory. Introdução à economia: princípios de micro e macroeconomia. Rio de Janeiro: Campus, 2001.

; ROMER; David; WEIL, David. A contribution to the empirics of economic growth. Quarterly Journal of Economics, v. 107, n. 2, May 1992.

MARCONI, Maria de Andrade; LAKATOS, Eva Maria. Técnicas de pesquisa. 4. ed. São Paulo: Atlas, 1999.

MINAYO, Maria Cecília de Souza. Quantitativo-qualitativo: oposição ou complementaridade? Cadernos de Saúde Pública, Rio de Janeiro, jul./set. 1993.

OLIVEIRA, Djalma de Pinho Rebouças de. Planejamento estratégico: conceitos, metodologia, práticas. 20. ed. São Paulo: Atlas, 2004.

PADOVEZE, Clóvis Luís. Contabilidade gerencial: um enfoque em sistema de informação contábil. 4. ed. São Paulo: Atlas, 2004.

PEREIRA, Carlos Alberto. Ambiente, empresa, gestão e eficácia. In: CATELLI, Armando (Org.). Controladoria: uma abordagem da gestão econômica — Gecon. São Paulo: Atlas, 1999.

PINDYCK, Robert S.; RUBINFELD, Daniel L. Microeconomia. São Paulo: Makron Books, 1994.

PRZEWORSKI, Adam. On the design of the state: a principal-agent perspective. In: SEMINÁRIO REFORMA DO ESTADO NA AMÉRICA LATINA E NO CARIBE. Proceedings... Ministério da Administração Federal e Reforma do Estado, Banco Interamericano de Desenvolvimento e Organização das Nações Unidas. Brasília, maio 1996.

RAM, R. Government size and economic growth: a new framework and some evidence from cross-section and time series data. American Economic Review, v. 76, 1986.

REZENDE, Fernando. Finanças públicas. 2. ed. São Paulo: Atlas, 2001.

REZENDE, Flávio da Cunha. Organizações e respostas institucionais a políticas de reformas do estado: um estudo de caso na administração direta do executivo federal brasileiro. Revista de sociologia e política, n. 14, jun. 2000.

ROCHA, C.; TEIXEIRA, J. Complementaridade versus substituição entre investimento público e privado na economia brasileira: 1965-1990. Revista Brasileira de Economia, v. 50, n. 3, jul./set. 1996. 
RUDIO, Franz Victor. Introdução ao projeto de pesquisa científica. Petrópolis: Vozes, 1993.

SLOMSKI, Valmor. Manual de contabilidade pública: um enfoque na contabilidade municipal, de acordo com a lei de responsabilidade fiscal. 2. ed. São Paulo: Atlas, 2003.

. Controladoria e governança na gestão pública. São Paulo: Atlas, 2005.

SOUSA, Edileusa Godoi; SOARES, Mara Alves; LEAL, Edvalda Araújo. A controladoria e as inovações tecnológicas na gestão pública: o caso governança eletrônica na prefeitura municipal de Uberlândia. In: CONGRESSO USP DE CONTABILIDADE, 5., São Paulo, 2005. Anais... São Paulo: FEA-USP, 2005.

SRINIVASAN, T. Neoclassical political economy, the state and economic development. Asian Development Review, v. 3, n. 2, 1985.

TESOURO NACIONAL. Informações sobre as finanças municipais. Disponível em: <www.tesouro.fazenda.gov.br/estados_municipios/index.asp>. Acesso em: 28 fev. 2005.

TORRES, Haroldo da Gama; FERREIRA, Maria Paula; DINI, Nádia Pinheiro. Indicadores sociais: por que construir novos indicadores como o IPRS. São Paulo Perspec., v. 17, n. 3-4, jul./dez. 2003.

VERHOEF, Erik T.; NIJKAMP, Peter. Externalities in the urban economy. TI 2003-078/3, 2003. (Tinbergen Institute Discussion Paper).

WONNACOTT, Paul; WONNACOTT, Ronald. Economia. 2. ed. São Paulo: Makron Books, 1994. 